\title{
Removal of Methylene Blue Dye Pollutant from Aqueous Solution Using Sugar Cane Bark and Chaff Biomass
}

\author{
Onyeocha V. ${ }^{1, a}$, Onwukamike K. N. ${ }^{1, b}$, Njoku V. O. ${ }^{2, d}$, Chidiebere M. A. ${ }^{1, c}$, \\ Oguzie E. E. ${ }^{1, e *}$ \\ ${ }^{1}$ Department of Chemistry, Federal University of Technology Owerri, PMB 1526, Owerri. Nigeria. \\ ${ }^{2}$ Department of Chemistry, Imo State University Owerri, PMB 2000, Owerri. Nigeria \\ avopapers@gmail.com, bliyingimr@gmail.com, 'supremeitltd@yahoo.com, \\ darinzechukwuchidiebere@gmail.com, eemekaoguzie@gmail.com*
}

Keywords: Dye; Adsorbent; Thermodynamic parameters; Biosorption; Supernatant solution; Biomass; Langmuir.

\begin{abstract}
The removal of Methylene blue (MB) dye pollutant from aqueous solution using sugar cane bark (SCB) and chaff (SCC) was studied using batch experiments. The operating variables studied were initial biomass dose, initial dye concentration, contact time, $\mathrm{pH}$ and temperature. The result revealed that the amount of $\mathrm{MB}$ dye uptake, $\mathrm{q}_{\mathrm{e}}(\mathrm{mg} / \mathrm{g})$ increased with an increase in temperature, dye concentration and contact time, but decreased with an increase in adsorbent dosage. Equilibrium data were found to obey Langmuir isotherm for both biomass, showing a monolayer adsorption mechanism. The monolayer sorption capacity of SCB and SCC for MB dye were found to be $1.282 \mathrm{mg} / \mathrm{g}$ and $1.706 \mathrm{mg} / \mathrm{g}$, respectively at $303 \mathrm{~K}$. The thermodynamics parameters of the MB / biomass system indicate spontaneous $\left(\Delta G^{\circ}<0\right)$ and endothermic $(\Delta H>0)$ process. The study show that SCB and SCC which are common environmental wastes can be used for the treatment of $\mathrm{MB}$ dye polluted water.
\end{abstract}

\section{Introduction}

Most industries use dyes and pigments to color their products [1]. Some of these industries include textile, tannery, food, paper and pulp, printing, carpet and mineral processing industries. Dyes and pigments are the serious polluters of our environment as far as color pollution are concerned [1]. Discharge of dye effluents into the natural streams is toxic to the aquatic lives. Color affects the nature of water and inhibits the sunlight penetration into the stream and reduces photosynthetic activity $[1,2]$. Some of the dyes are carcinogenic and mutagenic [3]. Color is a visible pollutant and the presence of even very minute amount of coloring substance in a pure medium makes it undesirable due to its appearance [4]. Removal of color from dye bearing wastewaters is a complex problem because of difficulty in treating such waste waters by conventional treatment methods $[1,4]$.

The most commonly used method for color removal is biological oxidation and chemical precipitation. However, these processes are effective and economic only in cases where the solute concentration is relatively high [5]. Currently sorption process has proved to be an effective alternative for the treatment of dye wastewaters. Activated carbon is the most commonly used adsorbent for this technique. It is obvious, that this method is not economic due to the high cost of activated carbon and also the additional cost involved in regeneration [6]. A process becomes economic, if the sorbent is inexpensive and does not require any expensive pretreatment. In recent years, some researchers have proved that agricultural by-product such as rice husk [7], cereal chaff [8], coir pith [9] and sawdust [10] could be used for the removal of MB dye from aqueous solution.

In this study, sorption studies were carried out using SCB and SSC for the removal of Methylene blue (MB) dye from aqueous solution. 


\section{Materials and Methods}

\section{Materials}

The sugar cane barks (SSB) and chaff (SCC) were all gotten from the sugar cane plant which was supplied from the Northern part of Nigeria. The processing of the two biomass was done differently after the initial peeling of the sugar cane plant to obtain the bark and extracting the liquid from the sugar cane (by chewing) to obtain the sugar cane chaff. The SCC was further allowed to ferrment in the presence of yeast. This was allowed to stand for a period of $24 \mathrm{~h}$. Both biomass were properly dried and sieved using a $250 \mu \mathrm{m}$ sieve.

The stock solutions of Methylene blue (MB) dye were prepared using distilled water. All working solutions were prepared by diluting the stock solution with distilled water to the desired concentration. Both biomass and $\mathrm{MB}$ solution were placed in a $30 \mathrm{ml}$ conical flask for adsorptive experiments. Fresh dilutions were used for each adsorption study.

\section{Methods}

Batch sorption experiments were carried out by shaking the flasks at $250 \mathrm{rpm}$ for a period of time using an electrical shaker (Model Labnet Orbit shaker, USA). Following a systematic process, the biosorption uptake capacity of $\mathrm{MB}$ dye in batch system was studied in the present work by measuring the absorbance of the MB dye solution before and after contact with the biomass. The parameters tested for include: contact time, biomass concentration, dye concentration and $\mathrm{pH}$. The equilibrium dye adsorbed $\left(\mathrm{q}_{\mathrm{e}}\right)$ were obtained from the equation below:

$$
\mathbf{q}_{\mathrm{e}}=\frac{\left(\boldsymbol{C}_{\boldsymbol{o}}-\boldsymbol{C}_{e} \boldsymbol{V}\right.}{\boldsymbol{W}}
$$

Where, $\mathrm{q}_{\mathrm{e}}(\mathrm{mg} / \mathrm{g})$ is the amount of dye adsorbed at equilibrium, $\mathrm{C}_{\mathrm{o}}$ and $\mathrm{C}_{\mathrm{e}}$ are the initial and final $\mathrm{MB}$ dye concentrations respectively in $\mathrm{mg} / \mathrm{L}, \mathrm{V}$ is the volume of the dye solution (L) and $\mathrm{W}$ is the mass of the dry biomass adsorbent $(\mathrm{g})$.

\section{Effect of contact time on biosorption}

Batch biosorption tests were done at different contacting times at the initial concentration of $90 \mathrm{mg} / \mathrm{L} \mathrm{MB}$ dye solution and chaff dose concentrations of $100 \mathrm{mg}$ for both SSB and SSC in $15 \mathrm{~mL}$ solutions. Agitation was made at a constant agitation speed of $250 \mathrm{rpm}$. The samples were then collected at 30,60, 90,120,150 and $180 \mathrm{~min}$ and were centrifuged and the left out concentration in the supernatant solutions were analyzed using UV-Vis Spectrophotometer (Model 752 UV-Vis Grating Spectrophotometer, China) by monitoring the absorbance changes at wavelength of maximum absorbance $(600 \mathrm{~nm})$.

\section{Effect of initial MB dye concentration}

Batch biosorption tests were carried out using a constant biomass dose of $40 \mathrm{mg}$ and varying $\mathrm{MB}$ dye concentrations $(30,60,90,120,150$ and $180 \mathrm{mg} / \mathrm{L})$ in a $15 \mathrm{~mL}$ solution. Agitation was made for $120 \mathrm{~min}$ at a constant agitation speed of $250 \mathrm{rpm}$. The left out concentration in the supernatant solution was analyzed using UV-Vis Spectrophotometer.

\section{Effect of chaff dose on biosorption}

Batch biosorption tests were done at the initial concentration of $90 \mathrm{mg} / \mathrm{L} \mathrm{MB}$ dye solution and the chaff dose 10, 20, 30, 40, 50 and 100mgin $15 \mathrm{ml}$ solutions. Agitation was made for $120 \mathrm{~min}$ at a constant agitation speed of $250 \mathrm{rpm}$. The samples were then centrifuged and the left out concentration in the supernatant solution was analyzed using UV-Vis Spectrophotometer.

\section{Effect of solution pH on biosorption}

The effect of $\mathrm{pH}$ on the amount of MB removal was analyzed over the $\mathrm{pH}$ values $2,4,6,8,10$ and 12. The $\mathrm{pH}$ was adjusted using $0.1 \mathrm{MNaOH}$ and $0.1 \mathrm{MHCl}$ solutions. In this study $15 \mathrm{ml}$ of $\mathrm{MB}$ dye solution of $90 \mathrm{mg} / \mathrm{L}$ concentration was agitated with $100 \mathrm{mg}$ of both sugar cane bark (SCB) and chaff (SSC). Agitation was made for $120 \mathrm{~min}$ at a constant agitation speed of 250 . The samples were then 
centrifuged and the left out concentration in the supernatant solution was analyzed using UV-Vis Spectrophotometer.

\section{Effect of temperature}

The effect of temperature on the rate of adsorption of MB dye was carried out at constant biomass dose $(100 \mathrm{mg})$ and dye concentration $(90 \mathrm{mg} / \mathrm{L})$. Batch experiments were carried out using magnetic stirrer at $250 \mathrm{rpm}$ at varying temperatures $\left(30,40,50,60\right.$ and $\left.70^{\circ} \mathrm{C}\right)$ in a thermostatic magnetic shaker. Agitation was made for $120 \mathrm{~min}$. The samples were then centrifuged and the left out concentration in the supernatant solution was analyzed using UV-Vis Spectrophotometer.

\section{Results and discussions}

\section{Effect of contact time}

The effect of contact time on the amount of MB dye adsorbed from aqueous solutions using SCB and SCC is shown in Fig. 1. The results obtained showed that $\mathrm{q}_{\mathrm{e}}$ increased from $0.45 \mathrm{mg} / \mathrm{g}$ to $1.575 \mathrm{mg} / \mathrm{g}$ and from $0.75 \mathrm{mg} / \mathrm{g}$ to $1.8 \mathrm{mg} / \mathrm{g}$ as contact time was increased from $30 \mathrm{~min}$ to $180 \mathrm{~min}$ for SCB and SCC respectively. For SCB there was a rapid initial adsorption over 60 min, after which the adsorption rate decreased slightly to reach equilibrium at $150 \mathrm{~min}$, this was followed by no significant change in $\mathrm{q}_{\mathrm{e}}$ with increasing time. A similar result was obtained for SCC with an initial rapid increase in amount of dye adsorbed over the first $90 \mathrm{~min}$. This was followed by a slight increase in $\mathrm{q}_{\mathrm{e}}$ for the next 30 min until equilibrium was reached at $150 \mathrm{~min}$.

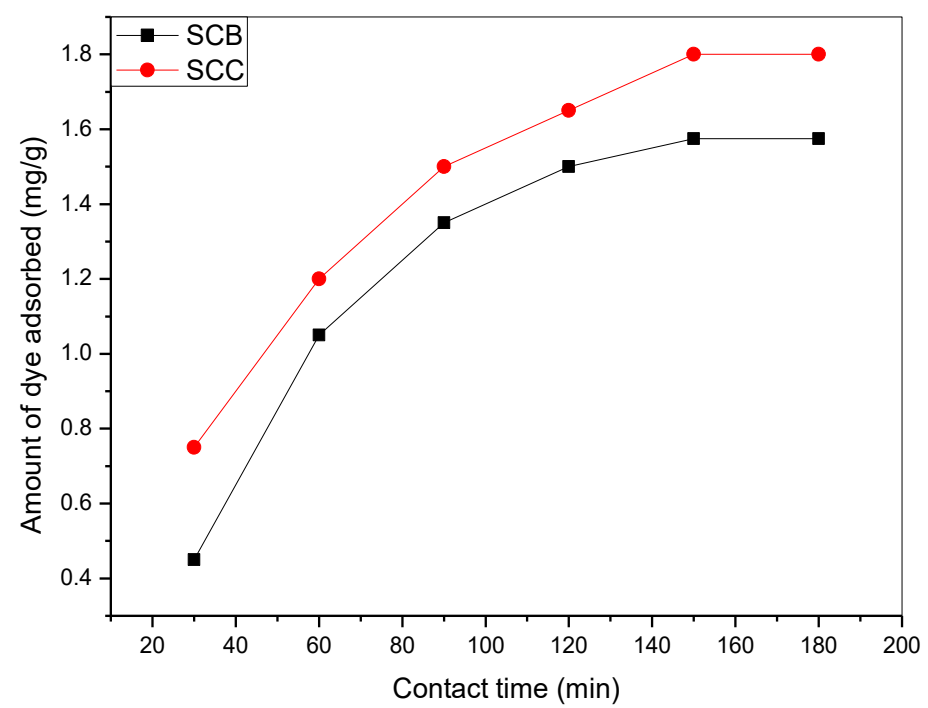

Fig. 1: Effect of contact time on the amount MB adsorbed by SCB and SCC at constant dye concentration $(90 \mathrm{mg} / \mathrm{L})$ and biomass dose $(100 \mathrm{mg})$.

After equilibrium was reached, increase in contact time was followed by no significant change in $\mathrm{q}_{\mathrm{e}}$. The initial rapid phase may be due to increased number of vacant sites available at the initial stage, resulting in an increased concentration gradient between adsorbate in solution and adsorbate on the adsorbent surface. This increase in concentration gradient tends to increase in dye sorption rate at initial stages. As time proceeds this concentration gradient gets reduced due to the accumulation of dye particles in the vacant sites, leading to decrease in adsorption rate at later stages after 60 and 90 min for SCB and SCC respectively. Ruping and coworkers reported a similar effect in their work on the removal of Methylene blue dye from aqueous solution using cereal chaff [11].

\section{The effect of initial MB concentration}

The effect of the initial concentration of $\mathrm{MB}$ on biosorption was shown in Fig. 2. From Fig. 2, the plots obtained show a relatively increase in the quantity of dye adsorbed with increasing initial dye concentration for both SCB and SCC. For SCB, increasing the dye concentration from 30 to $180 \mathrm{mg} / \mathrm{L}$ resulted in an increase in the quantity of $\mathrm{MB}$ dye adsorbed from 0.375 to $3.9375 \mathrm{mg} / \mathrm{g}$, 
while for SCC, increasing the dye concentration from 30 to $90 \mathrm{mg} / \mathrm{L}$ resulted to an increase in the quantity of MB dye adsorbed from 0.75 to $4.125 \mathrm{mg} / \mathrm{g}$.

The result obtained can be accounted for by the increase in driving force arising from the concentration gradient. Also at higher concentration of MB dye, the active sites of biomass will be surrounded by much more $\mathrm{MB}$ ions, thus increasing the rate at which adsorption process occurs. Hence the values of $q_{\mathrm{e}}$ increased with increasing of initial MB concentrations.

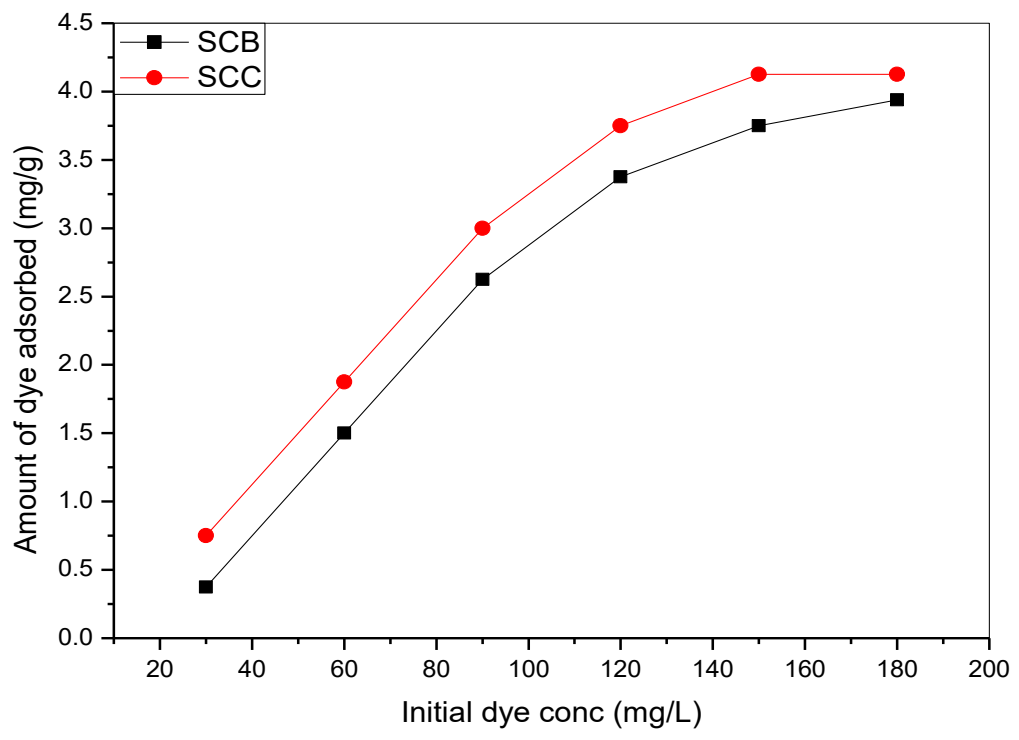

Fig. 2: Effect of Initial MB concentration on the amount of MB dye adsorbed by SCB and SCC at constant biomass dose (40mg).

\section{Effect of initial biomass dose}

The effect of biomass dose on the amount of $\mathrm{MB}$ adsorbed from aqueous solutions is shown in Fig. 3. The plots obtained show a relative decrease in the amount of dye adsorbed $\left(\mathrm{q}_{\mathrm{e}}\right)$ with increasing biomass dose.

The primary factor explaining this characteristic is that adsorption sites remain unsaturated during the adsorption reaction, whereas the number of sites available for adsorption site increases by increasing the adsorbent dose. Thus with increasing adsorbent dose, the amount of MB adsorbed per unit mass of biomass reduced, thus causing a decrease in $q_{\mathrm{e}}$ value. A similar effect has been previously reported [13].

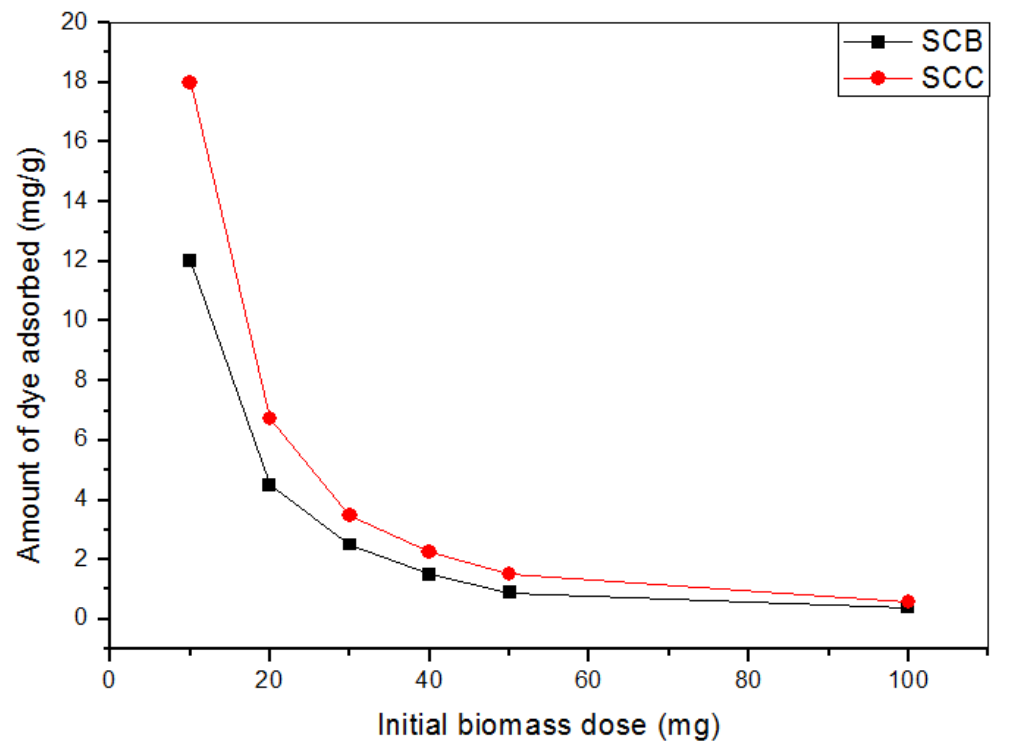

Fig. 3: Effect of biomass dose on amount MB adsorbed by SCB and SCC at constant dye concentration $(90 \mathrm{mg} / \mathrm{L})$. 


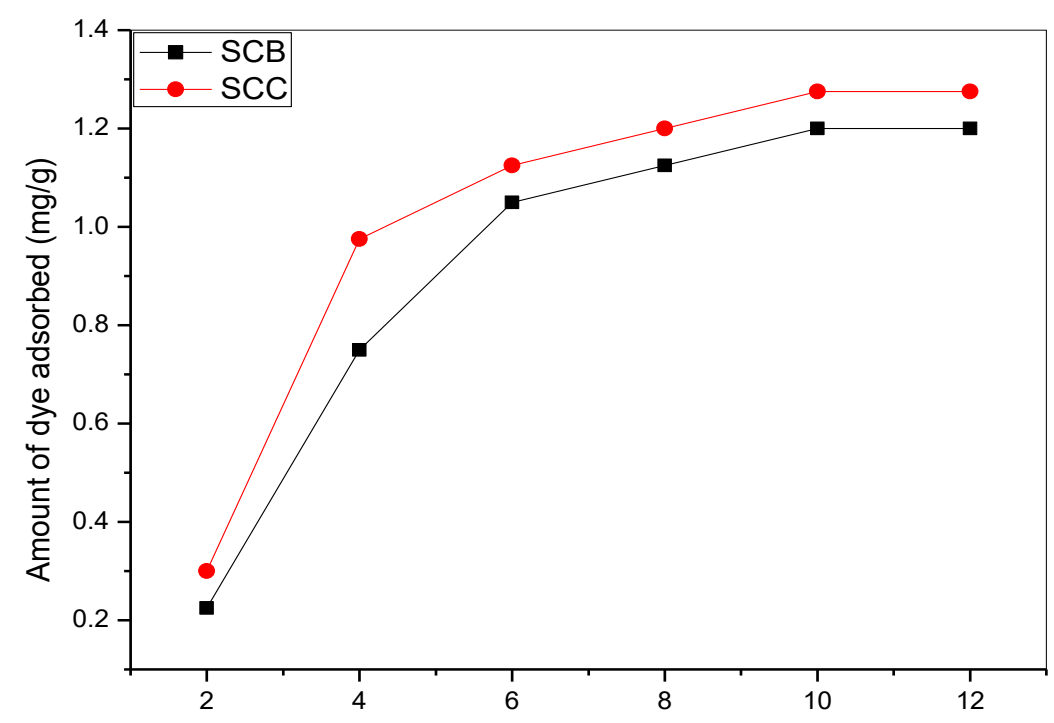

Fig. 4: Effect of $\mathrm{pH}$ on the amount MB adsorbed $\mathrm{by} \mathrm{SCB}$ and SCC at constant dye concentration $(90 \mathrm{mg} / \mathrm{L})$ and biomass dose $(100 \mathrm{mg})$.

\section{Effect of pH}

The effect of $\mathrm{pH}$ on the rate of biosorption of $\mathrm{MB}$ dye from aqueous solution is shown in Fig. 4. A relative increase in the quantity of dye adsorbed from 0.225 to $1.2 \mathrm{mg} / \mathrm{g}$ and 0.3 to $1.275 \mathrm{mg} / \mathrm{g}$ for $\mathrm{SCB}$ and SCC respectively was observed as $\mathrm{pH}$ increased. It was observed that the values of $q \mathrm{e}$ increased rapidly with the $\mathrm{pH}$ at early stage of $\mathrm{pH} 2$ to 4 , followed by a less rapid increase as $\mathrm{pH}$ increased from 6 to 10 while, the adsorption quantity was approximately constant in the $\mathrm{pH}$ range 10 to 12 .

Several reasons may be attributed to $\mathrm{MB}$ dye adsorption behavior of the sorbent relative to solution $\mathrm{pH}$. The solute (MB dye ions) uptake can be related to the active sites and also to the chemistry of the solute in the solution. At lower $\mathrm{pH}$ values, the surface of adsorbent would be surrounded by the hydrogen ions which compete with MB ions binding the sites of the adsorbent. At higher $\mathrm{pH}$ the surface of biomass particles may get negatively charged as a result of the ionization of the $\mathrm{OH}$ group in the cellulose-based biomass surface to produce negatively charged oxygen $\left(\mathrm{O}^{-}\right)$which enhances the adsorption of the positively charged dye cations through electrostatic forces of attraction.

\section{Effect of temperature}

The effect of temperature on the rate of biosorption of MB dye from aqueous solution is shown in Fig. 5. The plots obtained show a relative increase in the quantity of MB dye adsorbed from 6.90 to $9.75 \mathrm{mg} / \mathrm{g}$ and 7.20 to $10.35 \mathrm{mg} / \mathrm{g}$ as temperature increased from 313 to $353 \mathrm{~K}$ for SCB and SCC respectively. This observation can be accounted for by the increased mobility of MB dye ions in solution with increase in temperature. The increased mobility of the MB ions increases the probability of the dye molecules to be adsorbed by the SCB and SCC. A similar result was reported by Ruping and coworkers on MB removal using fallen phoenix leave [2]. 


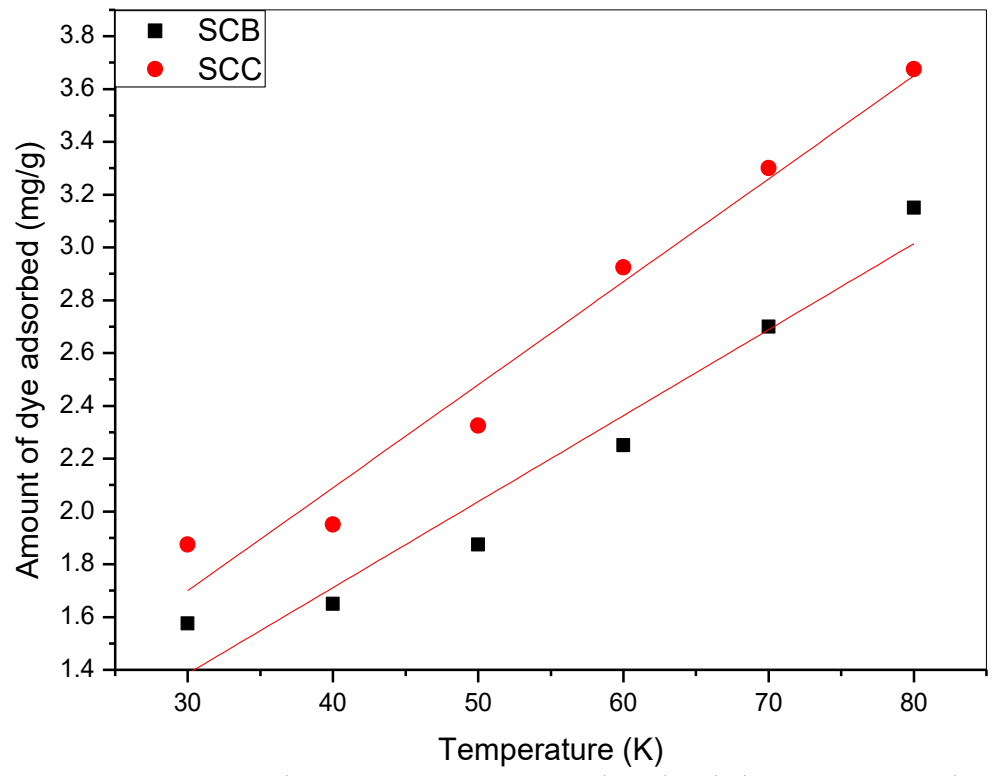

Fig. 5: Effect of temperature on the amount MB adsorbed by SCB and SCC at constant dye concentration $(90 \mathrm{mg} / \mathrm{L})$ and biomass dose $(100 \mathrm{mg})$

\section{Sorption equilibrium}

The analysis and design of sorption process requires the relevant adsorption equilibria, which is the most important piece of information in understanding an adsorption process [2]. Sorption equilibria provide fundamental physiochemical data for evaluating the applicability of sorption process as an unit operation. The two most commonly used equilibrium relations are Langmuir [14] and Freundlich [15] isotherm equations. In the present investigation the equilibrium data were analyzed using the Langmuir and Freundlich isotherm whose linear expressions are given by Eqs. (2) and (3), respectively:

$$
\begin{aligned}
\frac{C_{e}}{q_{e}} & =\frac{1}{K_{L} Q_{o}}+\frac{1}{Q_{o}} \mathrm{C}_{\mathrm{e}} \\
\log q_{e} & =\log K_{F}+\frac{1}{n} \log C_{e}
\end{aligned}
$$

where, $Q_{\mathrm{o}}$ is the maximum sorption capacity of the sugar cane biomass to uptake ethylene blue $(\mathrm{mg} / \mathrm{g})$ and $K_{\mathrm{L}}$ is the Langmuir constant related to the energy of adsorption $(\mathrm{L} / \mathrm{mg}), C_{e}$ is the equilibrium concentration of the dye $(\mathrm{mg} / \mathrm{L}), q_{\mathrm{e}}$ is the amount of dye adsorbed onto unit mass of biomass $(\mathrm{mg} / \mathrm{g}), K_{\mathrm{F}}$ and $n$ are Freundlich constants related to sorption capacity and sorption intensity of adsorbents.

Fig. 6 show Langmuir plots for SCB and SCC respectively while Fig. 7 show the Freundlich plot for SCB and SCC respectively.

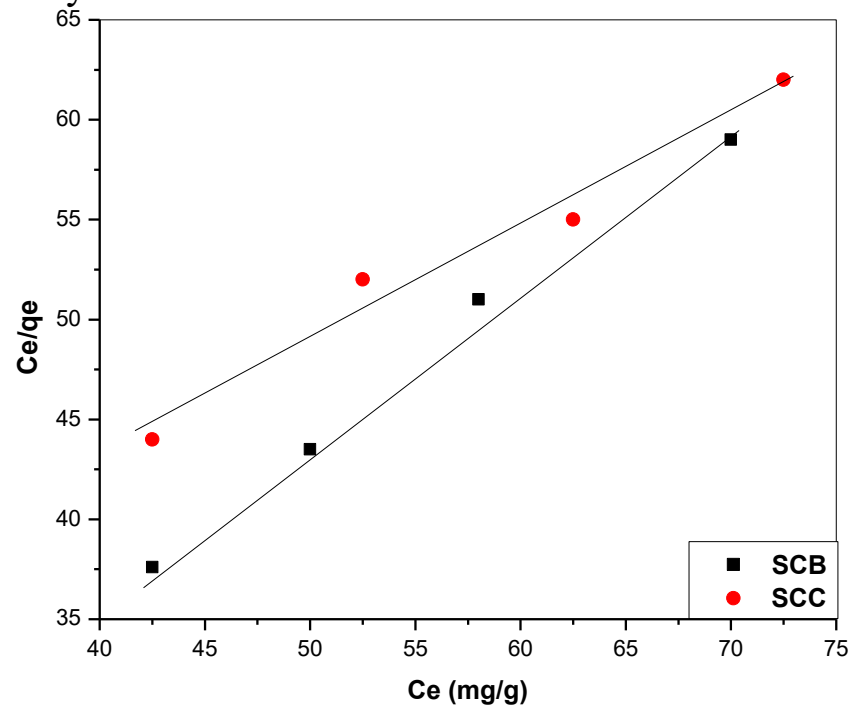

Fig. 6: Langmuir isotherm for SCB and SCC at 303K 


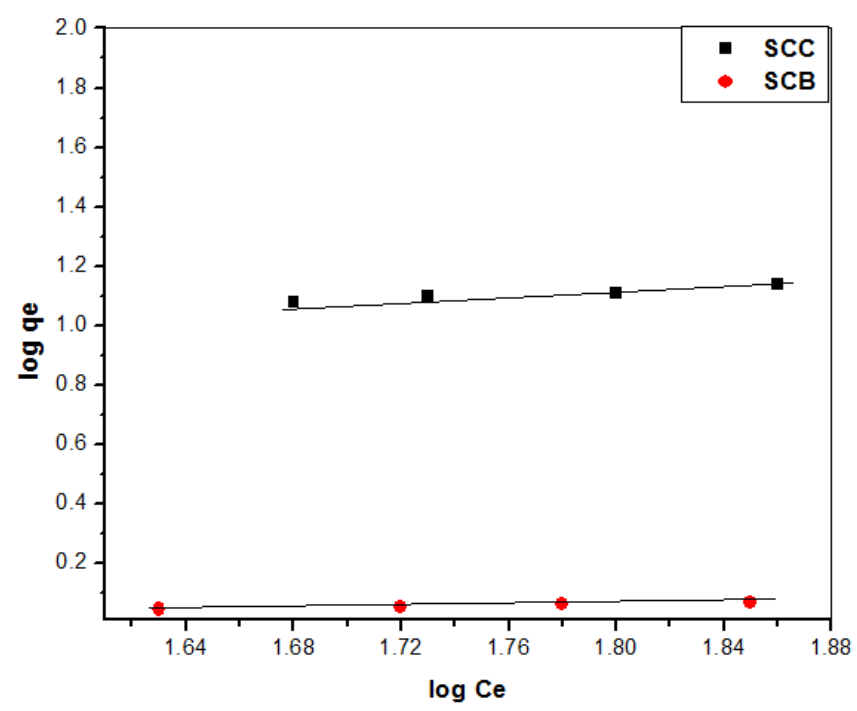

Fig. 7: Freundlich isotherm for SCB and SCC at 303K

The adsorption constants obtained for biomass A and B are summarized in the table below:

Table 1: Isotherm constants for MB sorption on SCC and SCB at 303K

\begin{tabular}{|l|l|l|l|l|l|l|}
\hline Biomass & \multicolumn{3}{|c|}{ Langmuir constants } & \multicolumn{3}{c|}{ Freundlich constants } \\
\hline SCB & $\mathrm{Q}_{0}=$ & $\mathrm{K}_{\mathrm{L}}=$ & $\mathrm{R}^{2}=0.99$ & $1 / \mathrm{n}=0.100$ & $\mathrm{~K}_{\mathrm{F}}=0.794$ & $\mathrm{R}^{2}=0.97$ \\
& $1.282 \mathrm{mg} / \mathrm{g}$ & $0.176 \mathrm{~L} / \mathrm{mg}$ & & & & \\
\hline $\mathrm{SCC}$ & $\mathrm{Q}_{0}=$ & $\mathrm{K}_{\mathrm{L}}=$ & $\mathrm{R}^{2}=0.97$ & $1 / \mathrm{n}=0.309$ & $\mathrm{~K}_{\mathrm{F}}=3.630$ & $\mathrm{R}^{2}=0.93$ \\
& $1.706 \mathrm{mg} / \mathrm{g}$ & $0.030 \mathrm{~L} / \mathrm{mg}$ & & & & \\
\hline
\end{tabular}

The results as represented in Figs. 6 and 7 show that the data for SCB and SCC obeys Langmuir and Freundlich isotherm. Table 1 shows the values for the various adsorption constants for MB sorption on SCB and SCC. As seen from the Table, the maximum monolayer adsorption for SCB $\left(\mathrm{Q}_{0}=1.282 \mathrm{mg} / \mathrm{g}\right)$ is less than that for $\mathrm{SCC}\left(\mathrm{Q}_{0}=1.706 \mathrm{mg} / \mathrm{g}\right)$. Also higher values of $\mathrm{K}_{\mathrm{L}}$ (affinity of the binding site or energy of adsorption) and $\mathrm{K}_{\mathrm{F}}$ (adsorption capacity) for SCC imply that SCC is a better adsorbent for MB removal from aqueous solution than SCB. The higher $\mathrm{R}^{2}$ obtained for the Langmuir than Freundlich isotherm for both SCB and SCC implies a monolayer adsorption mechanism.

\section{Thermodynamic parameters of MB biosorption onto Biomass A and B}

To estimate the effect of temperature on the adsorption of MB on SCB and SCC, the free energy change $\left(\Delta G^{\circ}\right)$, enthalpy change $\left(\Delta H^{\circ}\right)$, and entropy change $\left(\Delta S^{\circ}\right)$ were determined. The adsorption process can be summarized as representing a heterogeneous equilibrium. The apparent equilibrium constant $\left(K_{\mathrm{c}}^{\prime}\right)$ of the biosorption is defined as $[16,17,8]$ :

$$
K_{\mathrm{c}}^{\prime}=\frac{C_{\text {ad.e }}}{C_{e}}
$$

Where $c_{\mathrm{ad}, \mathrm{e}}$ is the concentration of $\mathrm{MB}$ on the adsorbent at equilibrium $(\mathrm{mg} / \mathrm{L})$. The value of $K_{\mathrm{c}}^{\prime}$ in the lowest experimental MB concentration can be obtained [18]. The $K_{\mathrm{c}}^{\prime}$ value is used in the following equation to determine the Gibbs free energy of biosorption $\left(\Delta G^{\circ}\right)$

$$
\Delta G^{\circ}=-R T \ln K_{\mathrm{c}}^{\prime}
$$

The enthalpy $\left(\Delta H^{\circ}\right)$ and entropy $\left(\Delta S^{\circ}\right)$ can be obtained from the slope and intercept of a Van't Hoff equation of $\Delta G^{\circ}$ versus $T$

$$
\Delta G^{\circ}=\Delta H^{\circ}-T \Delta S^{\circ}
$$

Where $\Delta G^{\circ}$ is the standard Gibbs free energy change $(\mathrm{J}), R$ the universal gas constant, $8.314 \mathrm{~J} \mathrm{~mol}^{-1}$ $\mathrm{K}^{-1}$ and $T$ is the absolute temperature $(\mathrm{K})$.

Values of $\Delta G$ for the biosorption process obtained from Eq. (5) are listed in Table 2. The negative $\Delta G^{\circ}$ values of $\mathrm{MB}$ at various temperatures is due to the fact that the adsorption processes are 
spontaneous with a high preference of $\mathrm{MB}$ on the Biomass and this negativity decreased with increase in temperature, indicating that the spontaneous nature of adsorption of $\mathrm{MB}$ are inversely proportional to the temperature [14].

Table 2: Thermodynamic parameters of MB sorption on SCB and SCC

\begin{tabular}{|c|c|c|c|c|c|}
\hline Temperature $(\mathrm{K})$ & & 323 & 333 & 343 & 353 \\
\hline \multirow[t]{3}{*}{$\mathrm{SCB}$} & $\Delta \mathrm{G}^{\circ}\left(\mathrm{KJmol}^{-1}\right)$ & -0.598 & -1.381 & -2.120 & -2.804 \\
\hline & $\Delta \mathrm{S}^{\circ}\left(\mathrm{KJmol}^{-1}\right)$ & \multicolumn{4}{|l|}{-0.068} \\
\hline & $\begin{array}{l}\Delta \mathrm{H}^{\circ} \\
\left(\mathrm{KJmol}^{-1} \mathrm{~K}^{-1}\right)\end{array}$ & \multicolumn{4}{|l|}{21.37} \\
\hline \multirow[t]{3}{*}{$\mathrm{SCC}$} & $\Delta \mathrm{G}^{\circ}\left(\mathrm{KJmol}^{-1}\right)$ & -1.087 & -2.059 & -2.885 & -3.492 \\
\hline & $\Delta \mathrm{S}^{\circ}\left(\mathrm{KJmol}^{-1}\right)$ & \multicolumn{4}{|l|}{-0.080} \\
\hline & $\Delta \mathrm{H}^{\circ}\left(\mathrm{KJmol}^{-1} \mathrm{~K}^{-1}\right)$ & \multicolumn{4}{|l|}{24.95} \\
\hline
\end{tabular}

The standard enthalpy and entropy changes of biosorption were determined from the Eq. (6) and values obtained for SCB were $21.37 \mathrm{kJmol}^{-1}$ and $-0.068 \mathrm{kJmol}^{-1} \mathrm{~K}^{-1}$ respectively. Values obtained for SCC for standard enthalpy and entropy changes were $24.95 \mathrm{kJmol}^{-1}$ and $-0.080 \mathrm{kJmol}^{-1} \mathrm{~K}^{-1}$ respectively. The positive value of $\Delta H^{\circ}$ confirms the endothermic character of biosorption on $\mathrm{MB}-$ biomass system, whereas, the negative $\Delta S^{\circ}$ value confirms the decreased randomness at the solidsolute interface during biosorption. The low value of $\Delta S^{\circ}$ obtained for both Biomass also indicates that no remarkable change on entropy occurred. The higher negative values obtained for $\Delta G^{\circ}$ show that the adsorption processes are spontaneous with a high preference of MB on the SCC than SCB.

\section{Conclusions}

The present study has shown the effectiveness of SCB and SCB (environmental wastes) in removing $\mathrm{MB}$ dye pollutant from aqueous solutions.

The obtained result revealed that the quantity of $\mathrm{MB}$ adsorbed onto biomass, $q_{\mathrm{e}}$ were dependent on contact time, initial MB concentration, biomass dose, solution $\mathrm{pH}$ and temperature.

The equilibrium data were found to follow Langmuir and Freundlich isotherms. The Langmuir monolayer saturation sorption value of MB was found to be $1.282 \mathrm{mg} / \mathrm{g}$ and $1.706 \mathrm{mg} / \mathrm{g}$ for SCB and SCC, respectively, showing that SCC has a higher adsorption potential than SCB.

The thermodynamics parameters calculated indicates spontaneous $\left(\Delta G^{\circ}<0\right)$ and an endothermic process $\left(\Delta H^{\circ}>0\right)$ for both Biomass studied.

\section{References}

[1] T. Robinson, G. McMullan, R. Marchant, P. Nigam, Remediation of dyes in textile effluent: a critical review on current treatment technologies with a proposed alternative, Bioresource Technol. 77 (2001) 247-255.

[2] Z. Aksu, Application of biosorption for the removal of organic pollutants: a Review, Process Biochem. 40 (2005) 997-1026.

[3] A. J. Linz, R. K. Greenham, L. F. Fallon, Methemoglobinemia: an industrial outbreak among rubber molding workers, J. Occup. Environ. Med. 48 (5) (2006) 523-8.

[4] G. Crini, Non-conventional low-cost adsorbents for dye removal: a Review, Bioresource technology. 97 (2006) 1061-1085.

[5] V. K. Gupta, I. Ali, M. D. Suhas, Equilibrium uptake and sorption dynamics for the removal of a basic dye (basic red) using low-cost adsorbents, J. Colloid Interface Sci. 265 (2003) 257264.

[6] Z. H. Wang, Z. Coomes, A, F. Haghseresht, The physical and surface chemical characteristics of activated carbons and the adsorption of methylene blue from wastewater, J. Colloid Interface Sci. 284 (2005) 440-446. 
[7] V. Vadivelan, K.V. Kumar, Equilibrium, kinetics, mechanism, and process design for the sorption of methylene blue onto rice husk, J. Colloid Interf. Sci. 286 (2005) 90-100.

[8] R.P. Han, Y.F. Wang, P. Han, J. Shi, Removal of Methylene blue from aqueous solution by chaff in batch mode, J. Hazard. Mater. 137 (2006) 550-557.

[9] J. Jeyanthi, M. Dhinakaran, Study of the removal of methylene blue from aqueous solution by using coir pith, Journal of Experimental Sciences. 3(9) (2012) 21-26.

[10] V. K. Garg, M. Amita, R. Kumar, R. Gupta, Basic dye (methylene blue) removal from simulated wastewater by adsorption using Indian rosewood sawdust: a timber industry waste, Dyes Pigments. 63 (2004) 43-250.

[11] H. Runping et al., Removal of methylene blue from aqueous solution by chaff in batch mode, Journal of Hazardous Materials. 137 (2006) 550-557.

[12] A. Gurses et al., Determination of adsorptive properties of clay/water system:Methylene blue sorption, J. Colloid Interface Sci. 269 (2000) 310-314.

[13] H. Runping et al., Biosorption of methylene blue from aqueous solution by fallen phoenix tree's leaves, Journal of Hazardous Materials. 141 (2007) 156-162.

[14] J. W. Harvey, A.S. Keitt, Studies of the efficacy and potential hazards of methylene blue therapy in aniline-induced methaemoglobinaemia, Br J Haematol. 54 (1983) 29-41.

[15] B. Mokhlesi, J. B. Leikin, P. Murray, T. C. Corbridge, Adult toxicology in critical care: Part II: specific poisonings, Chest Journal. 123 (3) (2003) 897-922.

[16] J. F. Saeman, Kinetics of wood saccharification: hydrolysis of cellulose and decomposition of sugars in dilute acid at high temperature, Industrial and Engineering Chemistry. 37(1) (1945) $43-52$.

[17] W. A. Sodeman, Bagasse Disease of the Lungs -- After 25 Years, Diseases of the chest. 52 (1967) 505-550.

[18] R. P. Han et al., Equilibrium biosorption isotherm for lead ion on chaff, J. Hazard. Mater. B125 (2005) 266-271. 